\title{
Opacidade homogênea no hemitórax esquerdo de mulher com 66 anos* $^{*}$
}

\author{
Vanessa Teixeira Barsalini Ruivo ${ }^{1}$, Vera Lúcia da Gama e Silva Volpe ${ }^{2}$, \\ NELSON MORRONE JUNIOR ${ }^{3}$, NELSON MORRONE ${ }^{4}$
}

Mulher branca, 66 anos, prendas domésticas, em uso de alfametildopa e hidroclorotiazida para tratamento de hipertensão arterial, queixou-se de fraqueza e emagrecimento de $20 \mathrm{~kg}$ em quatro meses e, havia 20 dias, de dor ventilatóriodependente na base do hemitórax esquerdo, além de tosse com escassa expectoração clara. Negava tabagismo e outras doenças atuais ou pregressas significativas.

Exame físico: Regular estado geral. P.A. 18 x 10. P e FC 80bpm. Obesa; eupnéica em repouso; mucosas descoradas; acianótica; afebril. Ausência de baqueteamento digital $e$ de adenopatias periféricas. Redução da expansibilidade do hemitórax esquerdo, com diminuição do murmúrio vesicular na mesma área; ausência de ruídos adventícios. Sem outras particularidades.

Exames: radiografia simples do tórax - Figura 1. Hemoglobina $8,9 \mathrm{~g} / \mathrm{dl}$; Ht $27 \%$; leucócitos - 4500/ml com diferencial normal, plaquetas $188.000 / \mathrm{ml}$; uréia $64 \mathrm{mg} / \mathrm{dl}$; creatinina $1,3 \mathrm{mg} / \mathrm{dl}$; urina I normal.

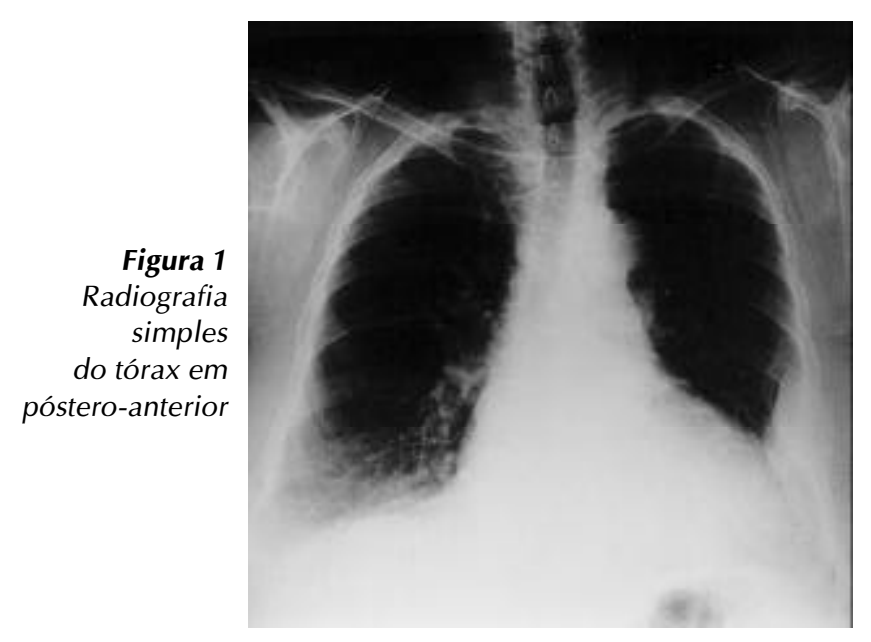

* Trabalho realizado no Sanatorinhos - Ação Comunitária de Saúde e Clínica Pneumológica do Hospital Ipiranga - São Paulo, SP.

1. Residente de $2^{\circ}$ ano em Pneumologia - Hospital Ipiranga.

2. Chefe da Clínica Pneumológica do Hospital Ipiranga.

3. Médico da Clínica Pneumológica do Hospital Ipiranga e de Sanatorinhos - Ação Comunitária de Saúde.

4. Diretor Clínico de Sanatorinhos - Ação Comunitária de Saúde.

Endereço para correspondência - Nelson Morrone, Rua Ministro de Godoy, 657, apto. 101 - 05015-000 - São Paulo, SP.

Recebido para publicação em 12/3/01. Aprovado, após revisão, em 25/6/01.

\section{Diagnóstico}

Mieloma múltiplo com envolvimento costal e massa extrapleural (plasmocitoma).

A radiografia do tórax em PA revela opacidade na base esquerda e claramente de origem extrapulmonar por sua forma e pelo ângulo formado com a pleura; este aspecto é sugestivo de mieloma múltiplo e a radiografia em oblíqua (Figura 2) revela nitidamente lise medular costal, com preservação da cortical, o que é patognomônico de mieloma múltiplo.

A complementação laboratorial revelou proteínas séricas totais de 9,9g/dl (albumina 3,1 e globulinas 6,8); mielogra-

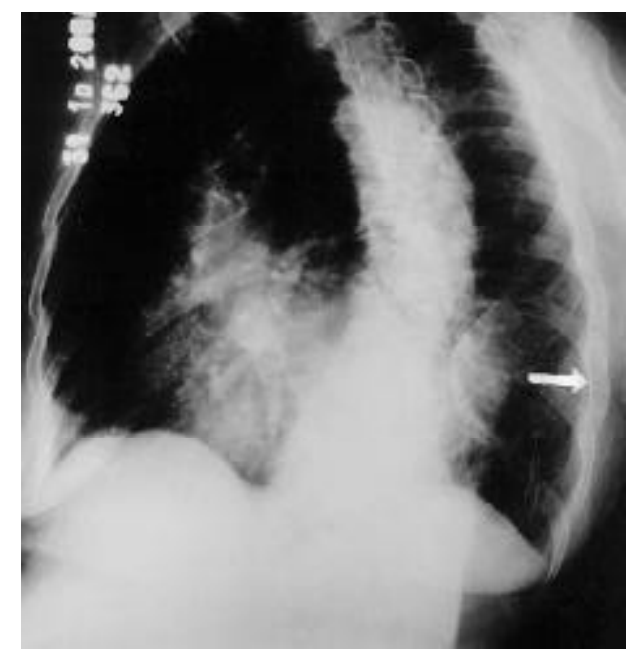

Figura 2

Radiografia simples do tórax em obliqua-anterior esquerda. Notar lise costal, com preservação da cortical.

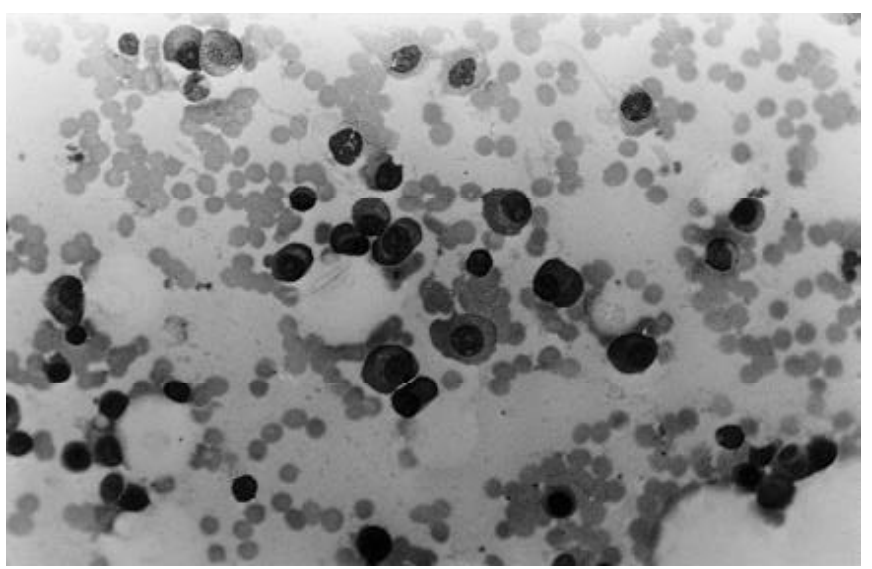

Figura 3 - Mielograma. Plasmocitose com atipia (aumento 200 x). 
ma (Figura 3) demonstrou infiltração plasmocitária com 57\% de plasmócitos atípicos. Radiografia do crânio revelou numerosas lesões líticas na calota. A paciente foi encaminhada para Serviço de Hematologia para tratamento.

\section{COMENTÁRIOS}

$\mathrm{Na}$ avaliação inicial, a radiografia do tórax em PA foi fundamental para o diagnóstico. A presença de massa extrapulmonar torácica é compatível com vários diagnósticos, como derrame pleural septado, fibroma pleural (antigamente chamado de mesotelioma benigno), mesotelioma, neoplasia metastática, seqüela de processos pleurais como tuberculose, pneumonia e infarto pulmonar, osteomielite inespecífica ou por tuberculose $e^{(1)}$ e traumatismo torácico. O comprometimento costal estreita a lista de possibilidades diagnósticas ${ }^{(2)}$, mas com freqüência a imagem costal na radiografia em PA é de difícil avaliação. A radiografia em oblíqua, como neste caso, tem vantagem de proporcionar melhor análise da massa e da costela; nesta incidência, ficou demonstrada a preservação da cortical, com lise da medular, levando ao diagnóstico de mieloma e tornando pouco prováveis outros diagnósticos. A determinação das proteínas séricas, o radiografia do crânio e principalmente o mielograma confirmam o diagnóstico.

As neoplasias plasmocitárias compreendem os plasmocitomas e o mieloma múltiplo, sendo a diferenciação feita pelo envolvimento de um só sítio ou de vários, respectivamente.

Os primeiros são caracterizados por massas isoladas, geralmente em tecidos moles; o tratamento é cirúrgico e o prognóstico excelente. Os plasmacitomas torácicos podem se localizar nos ossos ou no parênquima; na última eventualidade, o diagnóstico diferencial principal é com neoplasias e, portanto, prova citológica ou anatomopatológica é imperativa.

O mieloma múltiplo é o tumor ósseo primário mais comum e geralmente acomete os indivíduos após os 60 anos de idade; é doença maligna causada por proliferação de um clone único de plasmócitos e se caracteriza pela invasão da medula óssea pelos plasmócitos, presença de plasmocitomas e produção anormal de imunoglobulinas $\mathrm{G}$ ou $\mathrm{A}$ ou, raramente, $\mathrm{D}, \mathrm{E}$ e $\mathrm{M}$; é possivel ainda hipogamaglobulinemia e aumento isolado de proteínas de cadeia leve no soro ou na urina. Anemia, hemossedimentação alta, insuficiência renal e hipercalcemia geralmente também estão presentes.

No tórax, o mieloma múltiplo é responsável por alterações ósseas, pleurais e parenquimatosas. Nas últimas, o comprometimento pode ser devido à própria doença ou a complicações, como infecções, infartos e calcificações metastáticas ${ }^{(3,4)}$, o que ocorre em um décimo dos casos. Kintzer et al., revendo 958 pacientes, encontraram alterações torácicas em 444 (46\%), sendo $25 \%$ detectados quando do diagnóstico ${ }^{(3)}$. Gompels et al., por outro lado, verificaram que só 24 de 97 pacientes não apresentavam alterações em qualquer osso(5).
As anormalidades ósseas torácicas são as mais comuns, ocorrendo em um quarto dos pacientes, dos quais a quase totalidade apresenta comprometimento costal isolado ou associado a outras lesões ósseas; nas costelas as lesões podem ser de osteoporose, fraturas ou em sacabocados; $\mathrm{O}$ envolvimento costal mais típico é o da lise medular em sacabocado com preservação cortical, sendo freqüente a concomitância de massa subpleural com expansão para dentro do tórax; curiosamente, as lesões esternais se projetam para fora do tórax ${ }^{(3)}$. Tanto nas costelas quanto no esterno $e$ nos corpos vertebrais podem ocorrer fraturas que, por sua vez, podem ser responsáveis por insuficiência pulmonar grave ("tórax flácido")(6,7). O comprometimento ósseo é melhor demonstrado por radiografia que pelo mapeamento, porque a lesão é essencialmente osteoclástica; quando há fratura, entretanto, o mapeamento é mais sensível ${ }^{(8)}$.

A presença de massas subpleurais geralmente está associada a lesões costais, sendo admitido, nestes casos, que o prognóstico é pior, o mesmo ocorrendo na ausência de comprometimento costal. Melhor prognóstico estaria relacionado a comprometimento ósseo isolado e pela IgG como imunoglobulina anormal(5). O diagnóstico das massas pode ser feito por aspiração com agulha fina ou por biópsia; o último procedimento pode revelar ainda presença de amiloidose secundária e granulomas ${ }^{(9)}$.

Mais raramente o mieloma múltiplo também está associado a derrame pleural por complicação, principalmente por insuficiência cardíaca decorrente de amiloidose, ou pela própria doença. Nestes casos, é extremamente curioso que o derrame seja quase exclusivamente à esquerda (mais de 95\% das vezes), sendo possível demonstrar-se plasmocitomas atípicos e imunoglobulinas anormais no líquido pleural ${ }^{(3,10)}$.

\section{REFERÊNCIAS}

1. Ip M, Chen NK, So SY, Chin SW. Unusual rib destruction in pleuropulmonary tuberculosis. Chest 1989;95:242-244.

2. Hermann G, Abdelwahab IF, Berson BD, Greenberg ML, Palestro CJ. Case report. Skeletal Radiol 1990;19:379-381.

3. Kintzer JS Jr, Resenow EC, Kyle RA. Thoracic and pulmonary abnormalities in multiple myeloma. A review of 958 cases. Arch Intern Med 1978;727-730.

4. Weber CK, Friedrich JM, Merkle E, Prummer O, Hoffmeister A, Mattfeldt T, Firckhofen N. Reversible metastatic pulmonary calcification in a patient with multiple myeloma. Ann Hematol 1996;72:329-332.

5. Gompels BM, Votaw ML, Martel W. Correlation of radiological manifestations of multiple myeloma with immunoglobulin abnormalities and prognosis. Radiology 1972;104:509-514.

6. Abisheganaden J, Chee CBE, Wang YT. Use of bi-level positive airway pressure ventilatory support for pathological flail chest complicating multiple myeloma. (Case Study). Eur Respir J 1998;12:238-239.

7. Mansouri A. Flail chest and multiple myeloma. JAMA 1980;243:1036.

8. Young JWR. Metabolic and endocrine disorders affecting bone. In: Sutton $\mathrm{D}$, ed. Text book of radiology and medical imaging. $5^{\text {th }}$ ed. Vol 1 . Churchill Livingston, Edinburgh, 1992;219-240.

9. Gutmann EJ. Granulomatous inflammation related to amyloid deposition in a focus of multiple myeloma. Report of a case with diagnosis by fine needle aspiration biopsy. Acta Cytol 1995;39:739-7.

10. Deshpande AH, Nunshi MM. Pleural effusion as an initial manifestation of multiple myeloma. Acta Cytol 2000;44:103-104. 